\section{Equal-time resolution program for dialog management}

\section{DAVID SANDERS STODOLSKY \\ Aarhus School of Business Administration, Aarhus, Denmark}

Many procedures for allocation of turns to speakers have been advocated for both face-to-face dialog and teleconferencing (Stodolsky, 1978). Such procedures typically seek to promote a balance in participation through application of fair allocation rules. They sometimes incorporate protected modes of expression. such as anonymous voting, into the dialog management rules. In order to encourage concise statements and prompt treatment of a topic or motion, the rules often set limits on how long each person can speak and on the total time for conferencing.

The DIALOG program for the Apple II Plus computer uses an equal-time resolution rule to allocate time to speakers, and limits turns and total time to values entered at the beginning of conferencing (Stodolsky, 1981a). The equal-time resolution rule resolves conflicting requests for a turn in favor of the person who has thus far had the least time. The transition from speaker to speaker is protected in these cases, since the responsibility for either cutting off an over-time speaker or rejecting a pending request is shared by the group, as opposed to being the sole responsibility of the succeeding speaker, which is the case in unstructured dialog (Stodolsky, 1981b).

The program described here presents instructions that suggest that numbers (one through nine) be assigned to each speaker. A request to speak is submitted by holding up a card so that the operator can enter that number on the Apple II Plus keyboard. The request is verified by the display of that person's name at the bottom of the screen. Persons signal the operator when they are finished talking, and the operator enters a zero on the keyboard. The name of the next speaker then appears at the top of the screen and is announced by the operator. Alternatively,

The author's mailing address is: Institute for Organization and Management, Aarhus School of Business Administration. Ryhavevej 8, DK-8210 Aarhus V, Denmark. the current speaker's time runs out and the new speaker's name appears. In this case, the current speaker's request remains pending, and if that person's cumulative speaking time had been lower than that of other speakers with pending requests, the current speaker would have been granted an additional turn.

After presenting the instructions, the program then requests the turn limit, the total time limit, and number of participants. Each participant's name is then requested. After the last name is entered, the program presents the message "Waiting for new speaker," and starts timing the session. When the total time for conferencing is exceeded, the program permits the current speaker's turn to expire and then halts.

The program is written in Applesoft ${ }^{\circledast}$ BASIC and assumes a Mountain Hardware clock in slot 7. The part of the program that collects inputs is isolated in a subroutine to facilitate expansion of the number of speakers permitted or direct inputs from participants through individual keyboards. The display procedures are also isolated, which facilitates utilization of an external display generation device.

\section{Availability.}

A program listing is available without charge. DOS 3.3 copies of this and related programs that use up to four game paddles or an interface for up to 16 participants, and display elapsed speaking time when the program terminates, may be obtained by sending a blank diskette and $\$ 2$ to the author.

\section{REFERENCES}

STODOLSKY, D. (1978). Group conferencing with automatic mediation. In J. Belzer, A. G. Holtzman, \& A. Kent (Eds.), The encyclopedia of computer science and technology (Vol. 9). New York: Marcel Dekker.

SToDolsky, D. (1981a). Automatic mediation in group problem solving. Behavior Research Methods \& Instrumentation, 13, 235-242.

STodolsky, D. (1981b). Protected actions in dialog. In W. J. Reckmeyer (Ed.), Proceedings of the twenty-fifth annual North American meeting of the Society for General Systems Research, Louisville, KY: Society for General Systems Research.

(Manuscript accepted for publication August 17, 1984.) 